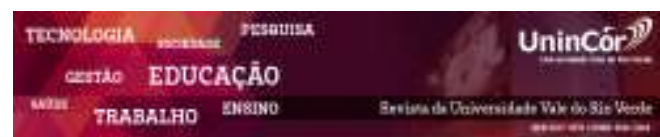

Revista da Universidade Vale do Rio Verde ISSN: / EISSN:

Vol. | n. | Ano 2018

Jacqueline Ramos

Universidade de Sorocaba

jackkie_ramos@hotmail.com

Daniel Bertoli Gonçalves

Universidade de Sorocaba

danielbertoli@bol.com.br

\section{PRODUÇÃO SUSTENTÁVEL DE CACHAÇA ARTESANAL}

\section{RESUMO}

Este artigo teve como finalidade descrever a cadeia produtiva da cachaça artesanal através da aplicação da ferramenta de Avaliação do Ciclo de Vida (ACV). A análise foi aplicada no setor agrícola e nos processos de produção da cachaça do Alambique Artesanal "Pinga dos Ramos", no município de Tatuí-SP. A coleta de dados foi realizada através da observação direta de cada etapa do processo e entrevista. A fim de integrar uma estratégia de prevenção ambiental na produção da cachaça aplicou-se o método de Produção Mais Limpa $(\mathrm{P}+\mathrm{L})$, cujo princípio é eliminar a poluição durante o processo de produção. Conclui-se que apesar da empresa em questão buscar ser sustentável em seus processos, há ainda várias possibilidades de se obter melhorias em seus sistemas produtivos, como a conversão do sistema produtivo para o sistema orgânico de produção, o que abre novas possibilidades mercadológicas para a empresa.

Palavras-chave: Cachaça Artesanal. Avaliação do Ciclo de Vida. Produção Mais Limpa. Cachaça Orgânica.

\section{SUSTAINABLE PRODUCTION OF HANDCRAFTED "CACHAÇA"}

\begin{abstract}
This article aimed to describe the productive chain of handcrafted "cachaça" through the tool's application of Life Cycle Assessment. The analysis was applied in the agricultural sector and in the productive processes of the "cachaça" from "Alambique Artesanal Pinga dos Ramos", Tatuí-SP, Brazil. The data collection was carried out through the direct observation of each stage of the process and interview. In order to integrate a strategy of environmental prevention in the "cachaça's" production, it was applied the method of Cleaner Production, which objective is to eliminate the pollution during the process of production. It concludes that, in spite of the enterprise to be sustainable in its processes, there are still several possibilities to obtain improvements in its productive systems, like the conversion of the productive system for the organic system of production, which opens new market's opportunities to the enterprise.
\end{abstract}

Keywords: Handcrafted "Cachaça". Life Cycle Assessment. Cleaner Production. Organic "Cachaça". 


\section{INTRODUÇÃO}

Observa-se, atualmente, uma maior preocupação com os impactos ambientais dos processos produtivos. Torna-se necessário para a sobrevivência das empresas, a adoção de medidas que levem a um desempenho ambiental satisfatório.

No caso do setor da agroindústria da cachaça artesanal, nota-se, o surgimento de novas estratégias empresariais, como a diversificação produtiva baseada em uma performance ambiental, como é o caso da produção orgânica de cachaça. A adoção desta estratégia ambiental objetiva atender um mercado consumidor que apresenta uma crescente tendência em valorizar produtos oriundos de sistemas orgânicos de produção.

A cana-de-açúcar cultivada no sistema orgânico tem contribuído para a redução do aquecimento global e da liberação de $\mathrm{CO}_{2}$ na atmosfera, evitando assim, a queima da palha, o uso de agrotóxicos e a adubação química, proporcionando benefícios sociais, econômicos e ambientais.

As estratégias preventivas relacionadas a gestão ambiental têm se expandido rapidamente desde a década de 80 sob uma gama de condições, como a Ecoeficiência, a Produção Mais Limpa, a Prevenção a Poluição e a Ecologia Industrial.

Deste modo, este artigo tem como objetivo levantar os aspectos e impactos ambientais gerados pelos processos de produção da cachaça artesanal nos setores agrícola e industrial do Alambique Artesanal "Pinga dos Ramos", por meio da Avaliação do Ciclo de Vida (ACV), e integrar, nos processos, a Produção Mais Limpa $(\mathrm{P}+\mathrm{L})$, a fim de gerar melhorias para a empresa.

A $\mathrm{P}+\mathrm{L}$ objetiva evitar ou reduzir a geração de resíduos durante o processo de produção, usando com eficiência materiais e energia renováveis, através de modificações nos processos produtivos, minimizando e reciclando os resíduos e emissões. Segundo esta metodologia, os resíduos gerados na produção devem ser manejados, ou seja, podem ser reutilizados, reciclados ou reprocessados.

O Alambique Artesanal "Pinga dos Ramos" atua no setor de bebidas destiladas desde 1.999 e está localizado na Fazenda São João, zona rural do município de Tatuí-SP.

As técnicas de coleta de dados utilizadas foram a observação direta participativa e entrevista, sendo esta realizada com o proprietário da empresa com o objetivo de levantar dados referentes aos seus processos produtivos bem como a reutilização de seus subprodutos.

\section{CACHAÇA ARTESANAL}

A cachaça é uma bebida genuinamente brasileira que surgiu no período colonial entre os escravos. Ela é produzida tanto artesanalmente em pequenos alambiques, quanto em grandes indústrias espalhadas pelo país (CIRIBELI; VELOSO, 2011, p. 30).

De acordo com o Centro Brasileiro de Referência da Cachaça - CBRC (2012), o Brasil possui capacidade instalada de produção de $\mathrm{Ca}$ chaça de aproximadamente 1,4 bilhão de litros. Atualmente, são mais de 40 mil produtores (4 mil marcas); este setor é responsável pela geração de mais de 600 mil empregos diretos e indi- 
retos. Os estados brasileiros que mais se destacam na produção da cachaça são: São Paulo, Pernambuco, Ceará, Minas Gerais e Paraíba.

Quando a produção da cachaça é orgânica e artesanal destaca-se pela qualidade diferenciada (SILVA et al., 2007, p. 01). De acordo com Margarido et al. (2009 apud MENEGHIN; BARBOZA, 2011, p. 03), existem atualmente nichos de mercado que procuram produtos diferenciados e, no caso da cachaça, prioriza principalmente uma escala de produção artesanal, cuja qualidade sensorial do produto obtido dificilmente é conseguida em escala industrial.

\section{Cana-de-açúcar}

A cultura da cana-de-açúcar é considerada uma das atividades responsáveis por desequilíbrios ecológicos no ambiente agrícola (EMBRAPA, 2007). De acordo com Langowski (2007 apud ALVARENGA; QUEIROZ, 2009, p. 02), os impactos negativos na área agrícola que mais merecem destaque são: redução da biodiversidade causada pela implantação canavieira; contaminação das águas superficiais e do solo através da prática excessiva de adubos, corretivos minerais, aplicação de herbicidas e uso desregulado de subprodutos da indústria; compactação do solo por conta do tráfego de maquinaria pesada durante o plantio, os tratos culturais e a colheita; e assoreamento de corpos d'água devido à erosão do solo em áreas de renovação de lavoura.

Segundo Oliveira (2008), o Brasil é o principal produtor mundial de cana-de-açúcar. Com solo e clima favoráveis ao seu cultivo, a atividade canavieira é uma das grandes propulsoras da agricultura brasileira.
De acordo com Cerveira (2002 apud OLIVEIRA, 2008, p. 07), o segmento da agroindústria é constituído principalmente por pequenos produtores que tem sua renda mensal ligada à produção de garapa, açúcar mascavo, rapadura e cachaça.

\section{Cachaça orgânica}

O setor agroindustrial canavieiro é perfeitamente capaz de reduzir os problemas ambientais que envolvem o modelo de produção dominante, sendo que alguns produtores têm apresentado técnicas de produção alternativas para a transformação do sistema, como é o caso da produção da cana orgânica (GONÇALVES, 2005, p. 225).

A principal diferença entre a cachaça convencional e a orgânica é que a cana-de-açúcar usada como matéria-prima é proveniente de práticas orgânicas de cultivo (MENEGHIN; BARBOZA, 2011, p. 02). De acordo com os mesmos autores, as etapas de produção da cachaça orgânica são as mesmas da cachaça convencional, porém nenhum aditivo químico pode ser acrescentando ao fermento. Todas as etapas de produção são devidamente registradas, o que proporciona rastreabilidade e controle de qualidade.

Desta forma, a produção orgânica obedece a normas rígidas de certificação que, além de proibir o uso de agrotóxicos e demais insumos químicos na agricultura, exige cuidados com a conservação e preservação dos recursos naturais (MENEGHIN; BARBOZA, 2011, p. 02).

Para Silva et al. (2007), a produção orgânica da cachaça artesanal enfrenta grandes desafios na concorrência com a cachaça industriali- 
zada, mas tem um significativo potencial de mercado externo. Geralmente o litro dessa cachaça chega a custar quatro vezes mais do que a cachaça industrial. Por outro lado, diante da realidade e vantagens pelo consumo de produtos orgânicos os consumidores estão cada vez mais se conscientizando e optando por estes produtos.

\section{Avaliação do ciclo de vida}

A ACV é um instrumento de gestão ambiental aplicável a bens e serviços. Refere-se aos aspectos ambientais de um produto em todos os seus estágios, desde a origem dos recursos, até a disposição final dos resíduos (BARBIERI, 2007, p. 164). Segundo o mesmo autor, também estão inclusas as etapas intermediárias, como beneficiamento, transporte, estocagem, etc. Esta ferramenta pode ser usada para se fazer uma análise vantajosa sob a óptica da Ecologia Industrial, que visa interligar o destino de materiais e de sua transformação em produto por meio de vários processos (GIANNETTI; ALMEIDA, 2006, p.43).

Segundo Ferreira (2004 apud NIGRI et al., 2010, p. 03), num estudo ACV de um produto ou serviço, todas as extrações de recursos e emissões para o ambiente são determinadas, quando possível, numa forma quantitativa ao longo de todo o ciclo de vida, desde que "nasce" até que "morre" ("from cradle to grave") e, a partir destes dados é que são avaliados os potenciais impactos nos recursos naturais, no ambiente e na saúde humana.

De acordo com a norma ISO 14.040 a $\mathrm{ACV}$ é composta por quatro etapas: objetivo e escopo, análise de inventário, avaliação de im- pacto e interpretação de resultados (NIGRI et al., 2010, p. 03).

\section{Produção mais limpa $(\mathrm{P}+\mathrm{L})$}

A $\mathrm{P}+\mathrm{L}$ é uma abordagem de proteção ambiental ampla que considera todas as fases do processo produtivo ou ciclo de vida do produto, com o objetivo de prevenir e minimizar os riscos para os seres humanos e o ambiente a curto e a longo prazos (BARBIERI, 2007, p. 135). Seu princípio básico é eliminar a poluição durante o processo de produção e não no final, usando com eficiência materiais e energia renováveis, minimizando e reciclando os resíduos e emissões, trazendo benefícios econômicos, à saúde ocupacional e ambiental.

De acordo com a Companhia Ambiental do Estado de São Paulo - CETESB (2002), os conceitos de $\mathrm{P}+\mathrm{L}$ consideram a geração de resíduos como desperdício de dinheiro por parte das empresas. Isso pelo fato de que o não reaproveitamento desses resíduos acarreta compra de insumos, desgaste de equipamentos e também custos envolvidos no transporte e armazenamento. A perda de dinheiro aqui é advinda pelo não aproveitamento dos resíduos ou uma possível eliminação desses mediante outros processos (ALVARENGA; QUEIROZ, 2009, p. 02).

Existem, além destas estratégias de $\mathrm{P}+\mathrm{L}$ para quando não se consegue evitar ou minimizar a geração do resíduos, e consistem basicamente em buscar outros usos para estes, através do reuso e da reciclagem. Desta forma, antes de determinar soluções de tratamento e destinação final dos resíduos já gerados, dentro ou fora do processo, é necessário que sejam verificadas alterna- 
tivas de redução da geração destes na fonte (CETESB, 2002).

\section{RESULTADOS E DISCUSSÃO}

\section{Objetivo e escopo}

Nesta etapa é apresentada uma avaliação do ciclo de vida da cachaça do Alambique Artesanal "Pinga dos Ramos". Também são discutidos os potenciais geradores de impactos ambientais durante o ciclo de vida da cachaça.

\section{Etapas do ciclo de vida da cachaça do Alam- bique Artesanal "Pinga dos Ramos"}

- Preparo do solo: O preparo do solo constituise num conjunto de ações capazes de criar condições ideais para o desenvolvimento da lavoura, o qual se descreve em sequência: gradagem pesada, aplicação de calcário, subsolagem, aração com arado de aiveca, gradagem média e terraceamento.

- Plantio: São realizadas diversas operações: sulcação com adubação, transporte e distribuição das mudas, fechamento dos sulcos.

- Colheita: A colheita é efetuada manualmente no período de junho a dezembro, e não precedida pela despalha a fogo. A ponteira da cana é utilizada para a alimentação animal, já a palha é utilizada como cobertura morta.

- Transporte: É realizado em carreta puxada por trator, em um procedimento entre 6 e 7 horas diárias, para suprir a demanda.
- Moagem: A cana é conduzida para a moagem logo após a colheita, ficando o menor tempo possível armazenada, pois a demora na moagem pode prejudicar a fermentação. Como subproduto do processo, tem-se o bagaço de cana que em parte é utilizado como combustível na caldeira e parte na produção de ração animal. O óleo e graxa utilizados na manutenção da moenda são armazenados em tambores para o reuso no tratamento e conservação de madeiras e palanques da fazenda.

- Decantação: Consiste na remoção do material em suspensão, realizado através do peneiramento e da decantação. Esse caldo geralmente contém terra, bagacilho.

- Fermentação: Nesta etapa, o caldo é transferido de uma só vez para a dorna contendo o fermento (pé-de-cuba). Quando a superfície do mosto estiver tranquila, é sinal de que o processo parou. Verifica-se a atenuação do brix do mosto, através do sacarímetro, onde a leitura deve ser zero ou pouco abaixo de zero. Aguarda-se também o período necessário para a decantação do fermento (2 a 4 horas). Em seguida, retira-se o vinho (mosto fermentado), retendo o pé-de-cuba no fundo da dorna e encaminhando-o até a destilação. A fermentação varia de 18 a 24 horas e é feita em dornas de aço, utiliza-se um fermento feito à base de farelo de milho e garapa.

- Destilação: O processo de destilação utiliza madeira adquirida de restos de construções e também o bagaço de cana seco como energia térmica. Conforme ocorre a fermentação, são produzidos de 80 a 120 litros de cachaça. De 
uma tonelada de cana, são extraídos 500 litros de caldo de cana. A propriedade possui fonte própria de água e toda água utilizada no processo é reaproveitada para limpeza do estabelecimento. O bagaço da cana, além de ser utilizado como combustível, também é utilizado como suprimento para alimentação de animais da fazenda. A cabeça e cauda da destilação são utilizadas para limpeza. A vinhaça obtida é usada como suplementação alimentar de ruminantes. As cinzas geradas pela queima do bagaço e da madeira na caldeira são peneiradas e aplicadas a solos de cultivo, contribuindo para a elevação da produtividade, devido sua riqueza em potássio. A cachaça recém destilada é armazenada em cisterna num período de 6 meses e passa por um período de envelhecimento de 1 a 3 anos em tonéis de carvalho. O processo de engarrafamento é feito através de envasadora manual. A venda é feita no próprio local. Após a venda, as garrafas utilizadas para fornecer o produto aos clientes são retornáveis, assim, são reutilizadas após a esterilização no processo de engarrafamento.

\section{Análise do inventário}

\section{Apresentação dos dados}

Com base no fluxo de entradas e saídas, é apresentado o balanço ecológico do processo produtivo da cachaça do Alambique Artesanal "Pinga dos Ramos" no setor industrial.

\section{- Quantidades de entradas no processo:}

Matéria-prima: 01 ton de cana-de-açúcar.

Materiais auxiliares: $500 \mathrm{~L}$ de caldo com $17^{\circ}$ Brix; 79,2 L de água potável para diluição do caldo para preparar o pé-de-cuba; $4 \mathrm{Kg}$ de farelo de milho para correção do mosto.

\section{- Quantidades de saídas do processo:}

Produto: 120 L de cachaça (fração coração).

Subprodutos: $480 \mathrm{~L}$ de vinhaça; $52 \mathrm{Kg}$ de cinzas (queima do bagaço e lenha); 8 a $10 \mathrm{~L}$ de cabeça e 20 a $35 \mathrm{~L}$ de cauda.

Resíduos: $204 \mathrm{Kg}$ de palha e ponta da cana; 265 $\mathrm{Kg}$ de bagaço e bagacilho.

Efluentes: $500 \mathrm{~L}$ de água utilizada na assepsia da moenda, coadores, tanques de decantação, recepção e tubulações; $2.000 \mathrm{~L}$ de água utilizada na dorna de condensação e; $20 \mathrm{~L}$ a cada 3 meses de óleo/graxa utilizados na manutenção da moenda.

Emissões: $432,48 \mathrm{Kg}$ de $\mathrm{CO} 2$ e 4,3 Kg de material particulado.

\section{Avaliação do impacto do ciclo de vida}

Os principais impactos ambientais negativos avaliados neste estudo são: o descarte da vinhaça e emissões atmosféricas.

A vinhaça quando descartada em corpos d'água provoca danos de difícil mensuração ambiental, social e econômica. Nesta unidade industrial são obtidos $480 \mathrm{~L}$ de vinhaça, portanto, pode ser absorvida pelo próprio sistema de produção de cachaça, transformando em suplemento alimentar de ruminantes da fazenda.

As emissões de $\mathrm{CO}_{2}$ e material particulado são poluentes atmosféricos associados a doenças pulmonares inflamatórias, e suas emissões estão presentes no processo de destilação através da queima da madeira e do bagaço de cana. Os dados de emissões de $\mathrm{CO}_{2}$ e material particulado 
foram obtidos baseado nas referências citadas a seguir. Segundo dados da Native (2009 apud NIGRI et al. 2010, p. 09), a quantidade média de material particulado resultante da utilização de bagaço como combustível, é da ordem de 13 $\mathrm{Kg} /$ tonelada de bagaço e, cerca de um terço do bagaço é utilizado como combustível. De acordo com Etanol Verde (2009 apud NIGRI et al. 2010, p. 09), em relação às emissões de $\mathrm{CO}_{2}$, a fermentação e a queima do bagaço produzem $3.604 \mathrm{Kg}$ de $\mathrm{CO}_{2}$ para produção de 1.000 litros de etanol, porém, uma tonelada de cana-de-açúcar produz 80 litros de etanol, desta maneira foi possível realizar a conversão para a produção de cachaça.

\section{Interpretação dos resultados}

Sabe-se que, quanto maior o volume de produção, maior será o impacto gerado ao meio ambiente. Em pequenas produções, como é o caso da empresa estudada, onde são gerados poucos resíduos, o próprio ambiente possui a capacidade de absorvê-los, porém, as preocupações ambientais são existentes.

Verificou-se, que a empresa não pratica queima do canavial e o destino final dos efluentes gerados nos processos de fermentação, destilação, lavagem de equipamentos, vasilhames e envase do produto são manejados de maneira correta.

Após analisar a cadeia produtiva da empresa, observou-se que é possível implantar melhorias no setor agrícola, bem como no setor industrial.

\section{Oportunidades de melhoria}

Após a realização do estudo detalhado, podem ser propostas algumas melhorias para a empresa, através da integração de medidas de produção mais limpa $(\mathrm{P}+\mathrm{L})$, como:

- Sistema orgânico de produção: A agricultura orgânica tem sido considerada como uma das alternativas de renda para pequenos agricultores devido à crescente demanda por alimentos saudáveis e ao forte apelo ecológico. É necessário realizar a conversão do sistema convencional para o orgânico de produção que varia de acordo com a cultura.

A cachaça orgânica e artesanal destacase pelo diferencial, através de suas características e sabor, e ainda pode receber maior valor de mercado ao passar pelo processo de envelhecimento e investimento em embalagem. Outro aspecto envolvido neste processo, é que a agricultura orgânica é considerada como uma estratégia de desenvolvimento e revitalização rural, constituindo-se numa forma de valorização do espaço, através do turismo rural, pois devido a necessidade de gestão do local, contribui para a proteção do meio ambiente e para a conservação do patrimônio natural.

\section{- Equipamento de controle de poluição (ECP)}

- multiciclone: Os ECPs são classificados em função do estado físico do poluente a ser considerado. Na empresa pode-se utilizar o multiciclone que é um elemento projetado para fazer a captação da fuligem arrastada pelos gases oriundos da combustão da caldeira.

- Fertirrigação: A utilização da vinhaça através da fertirrigação é uma tecnologia capaz de usar de forma racional os recursos naturais, pois ao mesmo tempo em que impede que ela seja despe- 
jada nos corpos d'água, possibilita a fertilização de solos agricultáveis.

Desta maneira, destaca-se o papel benéfico desse resíduo, que ao utilizar como fertilizante na lavoura substitui parcialmente a adubação mineral, reduzindo o custo da produção agrícola. A aplicação desse resíduo em doses compatíveis com as características físicas e químicas do solo, devido ao incremento de produtividade agrícola, aumenta também a produção de açúcar por hectare, tornando-se assim, um importante fator econômico principalmente para a produção da cachaça.

\section{- Coluna retificadora para produção de eta-}

nol: Ao invés de considerar como resíduo de pouco valor financeiro, a cabeça e a cauda podem ser transformados em álcool combustível, através da instalação de uma coluna retificadora, gerando rendimento extra para o produtor por eliminar gastos com a compra de combustível.

\section{CONSIDERAÇÕES FINAIS}

A sustentabilidade é de extrema importância a fim de assegurar a qualidade de vida para as gerações futuras, e para isso, é necessário que as empresas contribuam com práticas que garantam a preservação ambiental. Atualmente, muitas empresas vêm buscando se adaptar a estas novas práticas ambientais, através de processos produtivos que não causam danos ao meio ambiente.

Observa-se que a sustentabilidade já se tornou um fator de sobrevivência de muitas empresas e também da competitividade, bem como para a redução de custos dos processos produtivos.

Uma vez que na produção de um produto são gerados diversos subprodutos, como é o caso da produção da cachaça, é importante realizar um estudo aprofundado das etapas do processo, a partir da Avaliação do Ciclo de Vida, para que possa ser gerenciado um sistema ambiental preventivo, que vise melhorias no desempenho ambiental dos processos produtivos e consequentemente reduzindo perdas.

Através do detalhamento dos processos, foi possível direcionar o foco para a aplicação da Produção Mais Limpa, a qual procura soluções para os resíduos, valorando-os dentro do mesmo processo produtivo. Por outro lado, a situação observada na empresa estudada, demonstra que mesmo o pequeno produtor pode oferecer soluções ambientalmente sustentáveis de produção, por auxiliar substancialmente na redução de passivos ambientais através da atribuição de soluções eficientes e ambientalmente corretas para os resíduos gerados na atividade.

As etapas do processamento que podem tornar-se passíveis de implementação são, a aplicação da vinhaça em fertirrigação; a instalação de equipamento de controle de poluição do ar na chaminé; a instalação de uma coluna retificadora para a produção de etanol e; a conversão do sistema convencional para o sistema orgânico de produção da cana-de-açúcar.

Diante das considerações expostas, a diminuição dos impactos ambientais ocasionados tanto pelo cultivo da cana-de-açúcar quanto pelos resíduos gerados na produção da cachaça implica na reestruturação dos processos para se ob- 
ter um gerenciamento ambiental ainda mais eficiente.

\section{REFERÊNCIAS}

ALVARENGA, R. P.; QUEIROZ, T. R. Produção mais limpa e aspectos ambientais na indústria sucroalcooleira. In: $2^{\circ}$ Internacional Workshop Advances in Cleaner Production. São Paulo, SP, maio 2009. 9 p.

BARBIERI, José Carlos. Gestão ambiental empresarial: Conceitos, modelos e instrumentos. 2. ed. São Paulo: Saraiva, 2007. 382 p.

CBRC: Centro Brasileiro de Referência da Cachaça. O mercado da cachaça no Brasil. Disponível em: <http://www.expocachaca.com.br/assets/mercado-dacachaca.pdf $>$. Acesso em 30 maio 2012.

CETESB: Companhia Ambiental do Estado de São Paulo. A produção mais limpa $(\mathbf{P}+\mathrm{L})$ no setor sucroalcooleiro. Câmara ambiental do setor sucroalcooleiro. GT de P+L: Mudanças Tecnológicas - Procedimentos. São Paulo, SP, Nov 2002, 14 p.

CIRIBELI, J. P.; VELOSO, H. R. Descrição da cadeia produtiva da cachaça Guaraciaba: uma empresa que busca o desperdício zero. Revista gestão empresarial, Faculdade Governador Ozanam Coelho, Minas Gerais, v.1, n. 1, p. 30-43, jan-jun 2011.

EMBRAPA: Empresa Brasileira de Pesquisa Agropecuária. Pré-produção da cana-de-açúcar e meio ambiente. Disponível em: $<$ http://www.agencia.cnptia.embrapa.br/gestor/canade-

$\underline{\text { acucar/arvore/CONTAG01 } 57 \quad 711200516718 . h t m l}>$. Acesso em 27 maio 2012.

GIANNETTI, B. F.; ALMEIDA, C. M. V. B. Ecologia industrial: Conceitos, ferramentas e aplicações. 1. ed. São Paulo: Edgard Blüncher, 2006. 109 p.

GONÇALVES, Daniel Bertoli. Mar de cana, deserto verde? Dilemas do desenvolvimento sustentável na produção canavieira paulista. 2005. 256 f. Tese (Doutorado em Engenharia de Produção) - Universidade Federal de São Carlos, São Carlos, 2005.

MENEGHIN, M. C.; BARBOZA, R. A. B. Dossiê técnico: Produção de cachaça orgânica. Universidade Estadual Paulista, Sistema Integrado de Respostas Técnicas, ago 2011, 22 p.

NIGRI, Elbert Muller et al. Comparando processos industriais e artesanais: uma aplicação da análise simplificada do ciclo de vida na produção de cachaça. In:
XXX Encontro Nacional De Engenharia De Produção. Maturidade e desafios da Engenharia de Produção. São Carlos, SP, out 2010, 14 p.

OLIVEIRA, Fernanda Ribeiro de Andrade. Sustentabilidade e qualidade do solo em propriedades de cana-de-açúcar orgânica e convencional. 2008. 80 f. Dissertação (Mestrado em Agroecologia e Desenvolvimento Rural) - Centro de Ciências Agrárias, Universidade Federal de São Carlos, Araras, 2008.

SILVA, Leandro Sansão et al. A cachaça orgânica e artesanal e suas perspectivas nos mercados nacional e internacional. Centro Universitário Católico Salesiano Auxilium, Lins, SP, p. 01, 2007.

\begin{tabular}{l} 
Jacqueline Ramos \\
Bacharela em Engenharia Ambiental - Universidade \\
de Sorocaba. \\
\hline \\
Daniel Bertoli Gonçalves \\
Engenheiro Agrônomo e Dr. em Engenharia de \\
Produção. Docente e orientador do curso de \\
Engenharia Ambiental - Universidade de Sorocaba. \\
\hline
\end{tabular}

